\title{
A percepção de comportamentos relacionados à atenção plena e a versão brasileira do Freiburg Mindfulness Inventory
}

\author{
The perception of behavior related to mindfulness \\ and the Brazilian version of the Freiburg Mindfulness Inventory
}

\author{
Marcio Sussumu Hirayama ${ }^{1}$ \\ Daniela Milani ${ }^{1}$ \\ Roberta Cunha Matheus Rodrigues ${ }^{1}$ \\ Nelson Filice de Barros ${ }^{2}$ \\ Neusa Maria Costa Alexandre ${ }^{1}$
}

${ }^{1}$ Faculdade de Enfermagem, Faculdade de Ciências Médicas,Universidade Estadual de Campinas (Unicamp).

Cidade Universitária Zeferino Vaz, Distrito de Barão Geraldo. 13.030970 Campinas SP Brasil. sussuhira@gmail.com ${ }^{2}$ Departamento de Saúde Coletiva, Faculdade de Ciências Médicas, Unicamp.

\begin{abstract}
Mindfulness is a practice and a form of consciousness which has been the basis for innovative interventions in care and health promotion. This study presents mindfulness, describes and discusses the process of cultural adaptation of The Freiburg Mindfulness Inventory (FMI) to Brazilian Portuguese. From the original version of this pioneering instrument for assessing mindfulness two translations and two back-translations were made. These were evaluated by a committee of 14 experts (Buddhists, linguists, health professionals), who helped to create two versions for the first pre-test, based on which suggestions were made by a sample of 41 people of the population through interviews. Considering the difficulties in understanding the concepts that are unfamiliar to the Brazilian culture, a new version was prepared with additional explanations, which underwent a further evaluation of the experts and a second pre-test with 72 people. This process aimed at addressing the limitations and challenges of evaluating mindfulness in a country of western culture through a self-report instrument based on Buddhist psychology. With appropriate levels of clarity and equivalence with the original instrument, the Freiburg Mindfulness Inventory adapted for Brazil is presented.
\end{abstract}

Key words Translating, State of consciousness, Mind-body therapies, Meditation, Buddhism
Resumo Mindfulness é uma prática e um modo de consciência que tem sido base para intervenções inovadoras no cuidado e promoção da saúde. Este estudo apresenta mindfulness, descreve e discute o processo de adaptação cultural do Freiburg Mindfulness Inventory (FMI) realizado para a lingua portuguesa no Brasil. Da versão original deste instrumento pioneiro para avaliação de mindfulness foram criadas duas traduções, uma síntese e duas retrotraduções. Estas foram avaliadas por um comitê de 14 especialistas (budistas, linguistas, profissionais da saúde), que ajudaram a criar duas versões para o primeiro pré-teste no qual, por meio de entrevistas, foram levantadas sugestões de uma amostra de 41 pessoas da população. Considerando as dificuldades no entendimento dos conceitos não familiares à cultura brasileira, elaborou-se uma nova versão com explanações adicionais, a qual passou por uma nova avaliação dos especialistas e segundo pré-teste com 72 pessoas. Este processo buscou responder às limitações e desafios de se avaliar mindfulness em um país de cultura ocidental por meio de um instrumento de autorrelato fundamentado na psicologia budista. Com adequados níveis de clareza e equivalência com o instrumento original apresenta-se o Freiburg Mindfulness Inventory adaptado para o Brasil.

Palavras-chave Tradução, Estado de consciência, Terapias mente-corpo, Meditação, Budismo 


\section{Introdução}

Mindfulness é um tema ainda pouco familiar tanto para a população em geral quanto para a comunidade acadêmica brasileira. Ainda não há uma tradução consensual para este termo na língua portuguesa. Com isso, geralmente a própria palavra inglesa é utilizada ou ela é referida por meio das expressões "atenção plena", "observação vigilante", "mente alerta" e "consciência plena" dentre outras.

A palavra mindfulness é originária principalmente da tradução de "sati" (palavra proveniente do dialeto indiano denominado Pali). Sati literalmente significa lembrança ou lembrar. Dentro das escrituras budistas este termo remete à atividade da mente, à constante presença da mente e à lembrança de manter a consciência ${ }^{1}$.

Historicamente, mindfulness é um dos pontos centrais dos ensinamentos budistas ${ }^{2}$. Segundo esta tradição, a mente humana tende a se comportar de modo a avaliar e reagir emocionalmente fazendo com que o indivíduo se afaste do ato de sustentar sua consciência de momento a momento. Neste contexto, dimensões afetivas, éticas e o ato da vigilância (lembrar de manter a consciência) se integram em mindfulness, não como um estado fixo ou uma função mental, mas como uma prática, um processo dinâmico que pode estar inserido na vida como um todo, como uma forma de vida ${ }^{1,3}$.

Mindfulness também é visto como um construto que compartilha semelhanças conceituais com uma variedade de ideias provenientes da filosofia grega antiga, do pensamento da Europa ocidental (fenomenologia, existencialismo, naturalismo) e da América (transcendentalismo e humanismo $)^{4}$. Assim, pode ser considerado algo não estritamente religioso, oriental ou pertencente a uma determinada filosofia ou tradição ${ }^{3}$.

Alguns pesquisadores contemporâneos têm descrito mindfulness em dois componentes: um mais relacionado a processos cognitivos, a autorregulação da atenção mantida para a experiência imediata; e outro a processos emocionais, a adoção de uma postura de curiosidade, abertura e aceitação às experiências do momento presente ${ }^{5}$.

Ensinamentos tradicionais ${ }^{2}$ e uma recente meta-análise ${ }^{6}$ apontam que mindfulness pode ser desenvolvido por meio do hábito sistemático da meditação. Segundo a psicologia budista, a prática regular e contínua da meditação pode oferecer ao indivíduo um novo entendimento dos conceitos de si, de outro, do mundo, da sociedade e da natureza da experiência ${ }^{7}$. No contexto da terapia cognitiva, isso significa uma mudança de segunda ordem, na qual o objetivo não é mudar conteúdos (primeira ordem) e sim revisar ou transformar a perspectiva em que são vivenciados estes conteúdos, e os significados produzidos em relação a uma crença ou sentimento ${ }^{8}$.

A prática da meditação tem sido oferecida como uma estratégia de intervenção em diversos setores da sociedade 9 . Jon Kabat-Zinn (pesquisador americano e estudante do zen, vipassana e yoga) é considerado um dos pioneiros na expansão da utilização de mindfulness nos serviços de saúde atuais.

Em setembro de 1979, no centro médico da Universidade de Massachusetts, ele iniciou um programa que hoje é denominado Mindfulness based stress reduction (Redução do estresse baseado na atenção plena $)^{10}$. Este programa é realizado em grupo, tem a duração de dois meses, é composto por uma sessão de duas horas por semana, um encontro de um dia inteiro e orientações de práticas diárias a serem realizadas tanto em algum momento específico (inclusive com conduções por áudio) como durante as atividades cotidianas. Dentre os seus conteúdos ele oferece aos participantes atividades como: meditação sentada com atenção à respiração, às sensações do corpo, aos estados e conteúdos mentais, atenção em varredura com conscientização de cada parte do corpo (body scan), exercícios motores com plena consciência do corpo (posturas de yoga) e questionamentos com reflexões em grupo sobre as experiências ${ }^{9,11}$.

Desde a criação deste programa, inúmeras outras intervenções baseadas em mindfulness estão sendo utilizadas, investigadas e desenvolvidas para diferentes faixas etárias e populações específicas na área da saúde ${ }^{9,12,13}$. Algumas dessas intervenções têm mostrado grande efeito em diferentes populações ${ }^{6,14,15}$.

Neste movimento, a aplicação de mindfulness tem alcançado áreas como a formação profissional ${ }^{16}$, a educação de cuidadores ${ }^{17}$, a formação de professores $^{18} \mathrm{e}$ a gestão de serviços de saúde ${ }^{19}$. Na área clínica, sua utilização tem mostrado efeitos benéficos para uma ampla variedade de afecções, como depressão ${ }^{20}$, ansiedade ${ }^{20}$, dependência química ${ }^{21}$, distúrbios alimentares ${ }^{22}$, insônia ${ }^{23}$, dor crônica ${ }^{10,24}$, câncer ${ }^{25}$, fibromialgia, psoríases, artrite reumatoide, déficit de atenção e hiperatividade, HIV positivo, doenças cardíacas, dentre outras?.

Apesar do crescente interesse na sua aplicação e na descrição de seus efeitos, alguns autores ${ }^{26}$ enfatizam que as ideias do que é, e como mind- 
fulness opera, são facilmente mal-entendidas. Incluir mindfulness nos serviços oferecidos desafia os conceitos de cuidado e as práticas usuais dos profissionais de saúde. Assim, para a sua melhor compreensão eles propõem uma descrição na qual mindfulness apresenta características: ativas (observação das experiências internas e externas); passivas (não reação a estímulos atrativos ou aversivos); de não querer (não aspirar algo diferente, aceitar); de querer (não com desejo ávido, mas, por exemplo, querer com gentileza voltar a atenção ao presente); de não mudança (mindfulness não tem necessariamente o objetivo de reduzir os sintomas ou curar a doença); de mudança (do impacto do sintoma ou da doença pela modificação das percepções e atitude emocional do indivíduo); de não julgar e não reagir (inclui o julgamento cognitivo, como a identificação de categorias, mas não há julgamento emocional e motivacional, ou seja, a reação pode possuir calma mesmo diante de uma experiência triste ou desfavorável); e de aceitação passiva (não simplesmente aceitar tudo o que acontece, mas no sentido de suspender ou amenizar as reações emocionais e cognitivas em uma dada situação).

Com a expansão da utilização de mindfulness muitos questionários têm sido criados para a sua avaliação. Estes instrumentos têm sido objeto de debates $^{27,28}$, de estudos de revisão ${ }^{29-31}$ e têm auxiliado investigações sobre os seus possíveis mecanismos de ação e benefícios ${ }^{29}$.

Dentre mais de uma dezena de instrumentos disponíveis na literatura internacional ${ }^{31}$, até o momento apenas a Escala Filadélfia de Mindfulness (EFM) foi encontrada publicada e adaptada para brasileiros ${ }^{32}$. Outros dois questionários, os mais frequentemente citados na literatura, o Mindfulness Attention Awareness Scale e o Five Facets Mindfulness Questionnaire também foram adaptados para o português e estão em processo de publicação $0^{33}$. Incluindo esses três instrumentos, grande parte das medidas de autorrelato tiveram seus itens criados a partir de uma operacionalização de mindfulness inseridas em contextos da psicologia clínica ocidental com uma abordagem eclética e pragmática ${ }^{31,34}$.

Com uma abordagem diferente, o Freiburg Mindfulness Inventory (FMI) ${ }^{35,36}$ é um dos únicos que recebeu claras contribuições de especialistas da tradicional meditação mindfulness da psicologia budista no seu desenvolvimento ${ }^{31,34}$. Este instrumento foi criado em alemão ${ }^{35}$ e inglês ${ }^{36}$ e posteriormente adaptado para o francês $s^{37}$ e chinês ${ }^{38}$. Tem sido utilizado em países da Europa ${ }^{35,39-41}$, América do Norte $^{42-44}$ e Austrália ${ }^{45}$. A adaptação cultural do FMI para o português poderá instrumentalizar e incentivar o avanço da aplicação e investigações cuja base teórica esteja alinhada às raízes do conceito de mindfulness ${ }^{31}$. Este artigo tem o objetivo de descrever o processo de adaptação cultural do FMI realizado no Brasil.

\section{Método}

\section{Delineamento}

O processo metodológico de adaptação cultural do Freiburg Mindfulness Inventory foi realizado segundo as recomendações publicadas na literatura internacional atual ${ }^{46-48}$. Conforme ilustrado na Figura 1, as etapas seguidas para este estudo foram: a) duas traduções do instrumento

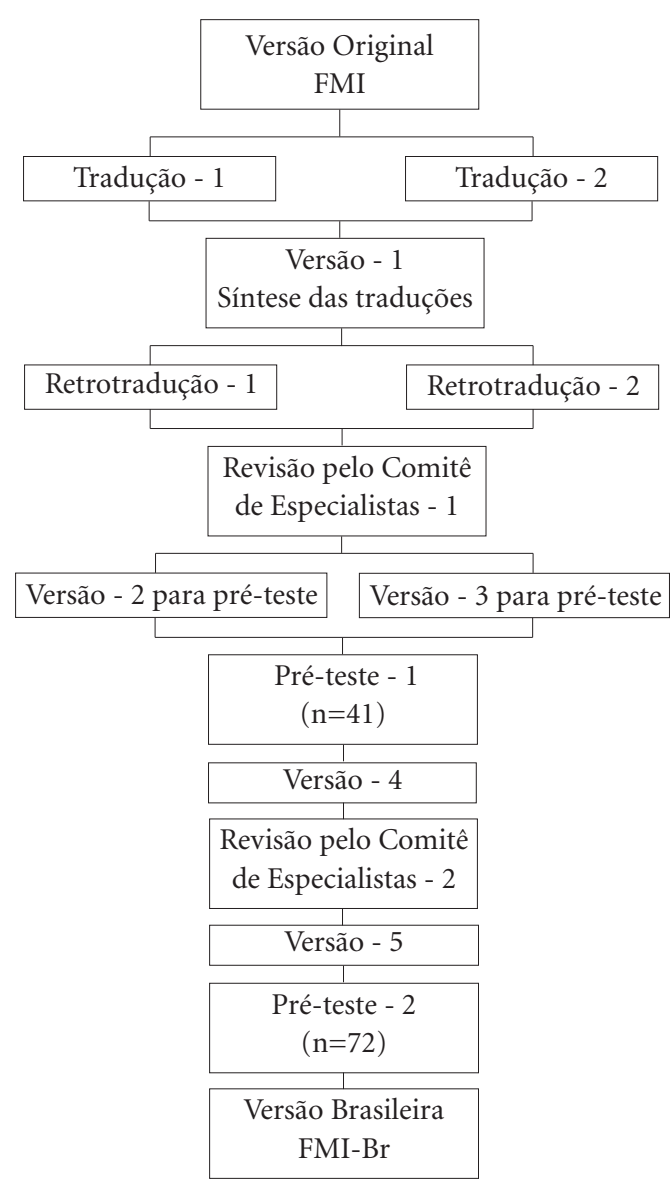

Figura 1. Processo de adaptação cultural do Freiburg Mindfulness Inventory (FMI) para a língua portuguesa no Brasil. 
original; b) síntese das traduções; c) duas retrotraduções para a língua original do instrumento; d) revisão pelo comitê de especialistas-1; e) pré-teste-1; f) revisão pelo comitê de especialistas-2; e g) pré-teste-2. Foram realizadas também a retrotradução da versão final e a sua apreciação pelo autor do instrumento original, Prof. Dr. Harald Walach, Institute of Transcultural Health Studies, Europa Universitat Viadrina, Frankfurt, Alemanha.

\section{$\mathrm{O}$ instrumento}

O Freiburg Mindfulness Inventory (FMI), no formato com 30 itens $^{35}$, foi um dos primeiros instrumentos de autoavaliação de mindfulness criado. Após cinco anos, foi publicada uma versão abreviada com 14 itens $^{36}$, a qual tem sido a mais utilizada.

O FMI tem como objetivo identificar, por meio da autopercepção do indivíduo, a frequência com que este vivencia comportamentos relacionados à mindfulness. Para cada item, o indivíduo deve assinalar sua resposta em uma escala tipo Likert de 4 níveis de frequência ( 1 = Raramente, 2 = De vez em quando, 3 = Com alguma frequência ou $4=$ Quase sempre). A pontuação total pode variar de 14 a 56 pontos. O resultado é obtido a partir da soma da pontuação de todos os itens, invertendo-se apenas a pontuação do item número 13. Quanto maior a pontuação obtida, maior é a percepção de mindfulness do indivíduo.

Apesar do estudo de criação ${ }^{36}$ e de outros ${ }^{42-45}$ terem utilizado o FMI como um instrumento unidimensional, recentes pesquisas ${ }^{39,40}$ têm identificado e dividido os itens do questionário em dois fatores: presença (itens 1, 2, 3, 5, 7 e 10) e aceitação (itens 4, 6, 8, 9, 11, 12, 13 e 14).

O FMI tem mostrado adequados níveis de consistência interna com alfa de Cronbach de 0,74 a $0,83^{37-39,42,45}$. Além disso, correlações significativas têm sido apresentadas com construtos avaliados por outros instrumentos como Questionário de Estado e Traço de Ansiedade ${ }^{38,39}$, Questionário de autoconsciência ${ }^{36}$, de experiências dissociativas $^{36}$, Escalas de depressão autorrelatada $^{38}$, depressão de Beck $^{39}$, autoestima ${ }^{38}$, estresse percebido ${ }^{37}$, autoeficácia ${ }^{37}$ e de afeto negativo e positivo $^{37}$. O FMI também tem apresentado adequados níveis de confiabilidade por meio do teste reteste com coeficiente de correlação intraclasse de $0,80^{37}$.

\section{Etapas da adaptação cultural}

\section{Tradução inicial}

A partir da versão original do instrumento com 14 itens na língua inglesa, foram realizadas duas traduções para a língua portuguesa. Estas foram feitas de forma independente por dois tradutores profissionais brasileiros.

Um dos tradutores possuía experiência com mindfulness e estava ciente dos aspectos a serem avaliados pelo questionário e seus objetivos. $\mathrm{O}$ segundo tradutor não foi informado sobre os conceitos abordados pelo instrumento e não tinha experiência na área do estudo ${ }^{45}$.

\section{Síntese das traduções}

Os pesquisadores, acompanhados por outros pesquisadores bilíngues e experientes na área de adaptação cultural de instrumentos, realizaram comparações, análise de concordâncias e discrepâncias das duas traduções para produzir a versão-1 do instrumento.

\section{Retrotradução}

A versão-1 foi traduzida de volta para a língua do instrumento original (inglês) com o objetivo de verificar possíveis erros, discrepâncias no conteúdo e/ou de significado entre o instrumento original e a versão traduzida.

A retrotradução foi realizada de forma independente por dois tradutores cuja língua materna é o inglês. Ambos não participaram da primeira etapa do estudo, não tinham experiência com mindfulness, não foram informados sobre os conceitos abordados pelo instrumento e não tinham conhecimento da versão original do instrumento ${ }^{45}$.

\section{Comitê de especialistas}

O comitê de especialistas foi constituído por 14 pessoas fluentes na língua portuguesa e inglesa e com experiência em adaptação cultural ou em orientação de práticas meditativas e mindfulness (três médicos, três linguistas, dois budistas ordenados, um enfermeiro, um fisioterapeuta, um biólogo, um cientista social, um dentista e um psicólogo).

Cada membro do comitê recebeu: um convite com as orientações para a participação no estudo, a versão original do instrumento, as duas traduções para o português, a versão síntese da tradução para o português, as duas versões das retrotraduções e um instrumento para avaliação das equivalências conceitual, idiomática, cultural e semântica das versões. 
O pré-teste é considerado um dos estágios finais de um processo de adaptação cultural. Esta fase avalia se a compreensão dos itens da versão adaptada mantém a sua equivalência com o original durante a aplicação do questionário. Para isto, recomenda-se aplicar o questionário em uma amostra de 30 a 40 pessoas com o objetivo de investigar a facilidade de compreensão e o que foi pensado para escolher as respostas ${ }^{46}$.

As amostras para o pré-teste foram por conveniência, inicialmente compostas pela comunidade que frequenta o campus de uma universidade pública paulista, a qual foi abordada nos saguões de entrada dos prédios. As amostras foram ampliadas pelo método bola de neve, no qual os próprios participantes puderam divulgar a pesquisa para outras pessoas.

Os critérios de inclusão para participação foram: nacionalidade brasileira, idade superior a 18 anos e habilidade suficiente para ler e responder sozinho o questionário no papel (pré-teste 1) ou no formato eletrônico (pré-teste 2).

\section{Pré-teste 1}

Buscando-se variabilidade quanto ao gênero, idade, escolaridade e nível socioeconômico foram recrutados 41 indivíduos (Tabela 1). Cada participante preencheu duas versões (2 e 3 ) do questionário e logo após respondeu uma entrevista individual cujo roteiro foi composto por perguntas abertas e de múltipla escolha, dentre as quais destacam-se: Você acha que as 14 afirmações foram suficientemente claras para você compreender o que cada item estava perguntando? Caso algum item não esteja claro para você, quais são? Porque eles não estão claros? O que você pensou na hora de respondê-los? Qual das duas versões (com ou sem texto ilustrativo) você achou mais fácil entender as perguntas? Justifique a sua resposta. $\mathrm{O}$ tempo dispendido para o preenchimento de cada uma das versões foi medido.

\section{Pré-teste 2}

No primeiro pré-teste os indivíduos apresentaram inúmeras dificuldades para o entendimen-

to do questionário o que indicou a necessidade de aprimorar a versão do instrumento. Esta nova versão foi avaliada e revisada novamente pelo comitê de especialistas e submetida a um novo pré-teste (pré-teste 2). Sugere-se que o pré-teste seja realizado em contextos semelhantes de usos futuros do questionário. Considerando o planejamento de investigar a consistência interna, reprodutibilidade teste reteste e outras propriedades psicométricas do instrumento quando aplicado em pessoas com experiência na prática meditativa e seus pares da população em geral por meio de questionários eletrônicos, optou-se por realizar o pré-teste-2 utilizando este mesmo ambiente virtual.

Nesta fase, o tamanho da amostra excedeu a orientação de 40 sujeitos $^{46} \mathrm{com}$ o intuito de ampliar a variabilidade da amostra no que se refere ao nível de escolaridade, com a inclusão de pelo menos $10 \%$ de participantes com ensino médio completo ou escolaridade inferior. Dessa forma, a amostra foi composta por 72 participantes com predomínio de mulheres, adultas jovens (idade média de 36 anos), com elevada escolaridade e renda familiar (Tabela 1).

Após preencher o questionário, os indivíduos responderam às perguntas relacionadas à clareza, dificuldade de entendimento dos itens e puderam fazer sugestões ou comentários. Para criação do questionário eletrônico e arquivamento sigiloso das respostas utilizou-se o software livre Lime Survey 1.92 e o servidor Lime Service (www.limeservice.com).

Para análise das respostas e comentários obtidos nas fases de pré-testes realizou-se análise temática para as questões abertas e análise estatística descritiva para as questões fechadas.

\section{Aspectos éticos}

Esta pesquisa está de acordo com a Resolução 196/1996 ${ }^{49}$ do Conselho Nacional de Saúde e foi aprovado pelo Comitê de Ética em Pesquisa da instituição. Após esclarecimento dos objetivos e procedimentos da pesquisa cada voluntário assinou um termo de consentimento livre e esclarecido ou o assinalou no formulário eletrônico.

Os pesquisadores deste estudo receberam autorização formal do autor do Freiburg Mindfulness Inventory original ${ }^{36}$ para realizarem o processo de tradução e adaptação cultural do instrumento no Brasil. 
Tabela 1. Características gerais da amostra do pré-teste-1 e do pré-teste-2 do Freiburg Mindfulness Inventory adaptado para o Brasil.

\begin{tabular}{|c|c|c|c|c|}
\hline \multirow[b]{2}{*}{ Característica } & \multicolumn{2}{|c|}{$\begin{array}{l}\text { Pré-teste-1 } \\
\text { Entrevistas }\end{array}$} & \multicolumn{2}{|c|}{$\begin{array}{c}\text { Pré-teste-2 } \\
\text { Questionários eletrônicos }\end{array}$} \\
\hline & $\mathbf{n}$ & $\%$ & $\mathbf{n}$ & $\%$ \\
\hline Total & 41 & 100 & 72 & 100 \\
\hline \multicolumn{5}{|l|}{ Gênero } \\
\hline Feminino & 23 & 56,0 & 57 & 79,2 \\
\hline Masculino & 18 & 44,0 & 15 & 20,8 \\
\hline \multicolumn{5}{|l|}{ Faixa etária } \\
\hline 18 a 35 anos & 24 & 58,0 & 47 & 65,3 \\
\hline 36 a 59 anos & 11 & 27,0 & 22 & 30,6 \\
\hline 60 anos ou mais & 6 & 15,0 & 3 & 4,2 \\
\hline \multicolumn{5}{|l|}{ Estado civil } \\
\hline Solteiro & 25 & 61,0 & 36 & 50,0 \\
\hline Casado & 10 & 24,4 & 29 & 40,3 \\
\hline Viúvo & 1 & 2,4 & 1 & 1,4 \\
\hline Divorciado/Separado & 5 & 12,2 & 6 & 8,3 \\
\hline \multicolumn{5}{|l|}{ Escolaridade } \\
\hline Fundamental incompleto & 2 & 4,8 & 2 & 2,8 \\
\hline Fundamental completo & 2 & 4,9 & 1 & 1,4 \\
\hline Médio completo & 15 & 36,6 & 5 & 6,9 \\
\hline Superior completo & 11 & 26,8 & 17 & 23,6 \\
\hline Pós-graduação & 11 & 26,8 & 47 & 65,3 \\
\hline \multicolumn{5}{|l|}{ Renda familiar } \\
\hline$<2 \mathrm{SM}$ & 4 & 9,8 & 3 & 4,2 \\
\hline 2 a 4 SM & 14 & 34,1 & 10 & 13,9 \\
\hline 5 a $6 \mathrm{SM}$ & 8 & 19,5 & 14 & 19,4 \\
\hline$>6 \mathrm{SM}$ & 15 & 36,6 & 45 & 62,5 \\
\hline \multicolumn{5}{|l|}{ Religião* $^{*}$} \\
\hline Nenhuma & 12 & 29,3 & 14 & 19,4 \\
\hline Católica & 19 & 46,3 & 34 & 47,2 \\
\hline Evangélica & 4 & 9,8 & 5 & 6,9 \\
\hline Outros & 7 & 17,1 & 25 & 34,7 \\
\hline \multicolumn{5}{|l|}{ Prática da meditação } \\
\hline Não & 30 & 73,2 & 54 & 75,0 \\
\hline Sim & 11 & 26,8 & 18 & 25,0 \\
\hline
\end{tabular}

*Alguns participantes apontaram ter mais de uma crença ou religião; SM: salários-mínimos.

\section{Resultados}

\section{Tradução inicial, síntese das traduções e retrotradução}

As duas primeiras traduções em português do FMI mostraram diferenças em algumas palavras. Por exemplo, o verbo "sense" foi traduzido como "sinto" ou "percebo" (item 2, Tabela 2) e "hectic" como "confusas" ou "agitadas" (item 12, Tabela 2), dentre outras pequenas diferenças.

Estas variações foram discutidas para a criação da versão-1. Na etapa seguinte, as duas retrotraduções desta versão-1 foram muito semelhantes entre si e com a versão original do instrumen- to. Dentre as poucas diferenças observadas "notice" e "gently" da versão original (item 3, Tabela 2) foram respectivamente expressas por "realize" ou "become aware" e "calmly" nas retrotraduções.

\section{Revisão pelo comitê de especialistas-1 e pré-teste-1}

A versão-1, em conjunto com as traduções e retrotraduções foram avaliadas pelo comitê de especialistas que expressou suas opiniões por meio de comunicações eletrônicas e encontros presenciais.

Além de mudanças de palavras, alguns membros do comitê apontaram: que não havia em 
Tabela 2. Os 14 itens e a escala de respostas do Freiburg Mindfulness Inventory: versão original, versão- 2, comentários mais comuns no pré-teste-1, número de pessoas que relataram falta de clareza no pré-teste-1 e versão-4.

\begin{tabular}{|c|c|c|c|c|}
\hline $\begin{array}{l}\text { versão original } \\
\text { Inglês }\end{array}$ & $\begin{array}{c}\text { versão-2 } \\
\text { Pré-teste-1 }\end{array}$ & $\begin{array}{l}\text { Exemplos de comentários } \\
\text { mais comuns ou } \\
\text { relevantes para a Versão-2 } \\
\text { Pré-teste } 1\end{array}$ & $\begin{array}{c}\text { Falta de } \\
\text { clareza para } \\
\text { a Versão-2 } \\
\text { Pré-teste } 1\end{array}$ & versão-4 \\
\hline
\end{tabular}

Rarely, Occasionally, Fairly often, Almost always

1. I am open to the experience of the present moment.

2. I sense my body, whether eating, cooking, cleaning or talking.

3. When I notice an absence of mind, I gently return to the experience of the here and now.

4. I am able to appreciate myself.

5. I pay attention to what's behind my actions.
Quase nunca,

De vez em quando, Frequentemente, Quase sempre 1. Estou aberto para viver a experiência do momento presente.

2. Eu presto atenção às sensações do meu corpo enquanto estou comendo, cozinhando, fazendo limpeza ou conversando.

\section{Quando percebo} que estou disperso ou desatento, calmamente retomo a minha atenção ao que estou vivenciando no momento presente.

4. Eu consigo perceber "Pergunta aberta, pensei e apreciar as minhas próprias qualidades.

5. Presto atenção ao que está por trás de minhas ações. "muito parecido 'de vez em quando' com 'quase nunca' e também 'frequentemente' com 'quase sempre";

"O que é estar aberto?"; "O que é experiência?”; "Que tipo de experiência?” "Momento presente, esse agora, ou cada momento?"

"Não entendi, acho que nunca pensei e não estou acostumada a fazer."

"Desatento?"; "O que seria calmamente retornar, e a quê?" também nos meus defeitos"

"Esse "por trás das minhas ações" seria alguma coisa ruim que pode acontecer, um lado negativo por trás do que estou fazendo ou bons também?” “O que minhas ações interferem nos outros?" "planejamento da ação? O que eu quero gerar?”
17 (41\%) Quase nunca, Poucas vezes, Algumas vezes, Quase sempre

1. Estamos abertos para a experiência do momento presente

$6(15 \%) \quad$ quando estamos dispostos a viver as coisas desconhecidas, agradáveis ou desagradáveis que surgem a cada instante.

- Com que frequência você esteve aberto para a experiência do momento presente?

$5(12 \%) \quad 2$. Quando estamos concentrados para realizar e terminar uma atividade, podemos não prestar atenção às sensações do nosso corpo. Também acabamos não sentindo o nosso corpo quando fazemos uma coisa, mas estamos pensando em outras.

- Com que frequência você sentiu o seu corpo quando estava comendo, cozinhando, fazendo limpeza ou conversando?

$4(10 \%) \quad 3$. Estamos dispersos quando ficamos imaginando o futuro, relembrando o passado ou pensando em coisas que não tem a ver com o local e atividade que realizamos no momento presente.

-Com que frequência você notou que estava disperso e retornou calmamente ao que estava vivendo no aqui e agora?

$2(5 \%) \quad 4$. Ficamos nos cobrando ou nos criticando. Podemos também reconhecer as nossas qualidades e apreciar a nós mesmos.

- Com que frequência você conseguiu apreciar a si mesmo?

$5(12 \%) \quad 5$. Prestamos atenção ao que está por trás das nossas ações quando olhamos para dentro de nós e identificamos o que nos levou a ter tomado certa atitude ou ter dito isso ou aquilo.

- Com que frequência você prestou atenção ao que está por trás de suas ações? 
Tabela 2. continuação

\begin{tabular}{|c|c|c|c|c|}
\hline $\begin{array}{l}\text { versão original } \\
\text { Inglês }\end{array}$ & $\begin{array}{c}\text { versão-2 } \\
\text { Pré-teste-1 }\end{array}$ & $\begin{array}{l}\text { Exemplos de comentários } \\
\text { mais comuns ou } \\
\text { relevantes para a Versão-2 } \\
\text { Pré-teste } 1\end{array}$ & $\begin{array}{c}\text { Falta de } \\
\text { clareza para } \\
\text { a Versão-2 } \\
\text { Pré-teste } 1\end{array}$ & versão-4 \\
\hline
\end{tabular}

6. I see my mistakes and difficulties without judging them.

6. Eu vejo meus erros
e dificuldades sem
ficar me julgando. $\quad$\begin{tabular}{l} 
tarefa errada?" \\
\hline
\end{tabular}
ficar me julgando.

7. I feel connected to my experience in the here-and-now.

\section{Eu me sinto conectado com a minha experiência do aqui-e-agora.}

"conectado?" “o que seria conectado com o presente?”; "o que quer dizer com experiência?"; "precisa ter calma pra entender o que está perguntando"

$\begin{array}{ll}\text { 8. I accept } & \text { 8. Eu aceito } \\ \text { unpleasant } & \text { experiências } \\ \text { experiences. } & \text { desagradáveis. }\end{array}$

9. I am friendly to myself when things go wrong.

10. I watch my feelings without getting lost in them.

\begin{abstract}
9. Quando as coisas dão errado, sou compreensivo e me dou bem comigo mesmo.
\end{abstract}

"que tipo de experiência desagradável?"; "como assim se eu aceito uma coisa desagradável, pela lógica ninguém quer fazer algo desagradável"; "eu aceito, é eu me conformo com?; "não é uma questão de aceitar, elas existem, senão a vida da gente é um horror"; "aceitar é diferente de reconhecer" "como é que quando as coisas dão errado eu posso ser compreensivo e me dar bem comigo mesmo? como isso é possível? Fica meio contraditório. quando dá errado, fica nervoso, se não fica, é um disfarce, máscara."

10. Eu observo minhas "se perder?"; "não entendi emoções, sem eu me muito bem, as emoções que eu perder nelas.
$2(5 \%)$

6. Podemos ficar criticando, cobrando e viver nos julgando por nossos erros e dificuldades. Podemos também reconhecer e conviver com eles. - Com que frequência você olhou para os seus erros e dificuldades sem ficar se julgando?

$12(29 \%) \quad 7$. Nos sentimos concentrados na experiência do aqui e agora quando nossa atenção está completamente no local onde estamos e na atividade que estamos realizando.

- Com que frequência você se sentiu concentrado na sua experiência do aqui e agora?

$11(27 \%) \quad 8$. Aceitamos experiências desagradáveis quando conseguimos conviver com uma notícia ou situação que não gostamos, sem querer mudá-las ou fugir delas. - Com que frequência você aceitou experiências desagradáveis?

4 (10\%) 9. Quando alguma coisa dá errado, existem inúmeras formas de tratarmos a nós mesmos. Podemos nos chatear e ficar nos condenando; ou, podemos tentar incentivar e apoiar a nós mesmos. - Quando as coisas deram erradas, com que frequência você apoiou a si mesmo?

7 (17\%) 10. Observamos nossas emoções sem nos perder nelas quando olhamos as nossas próprias emoções e conseguimos ter clareza para pensar e fazer as coisas com consciência. - Com que frequência você observou suas emoções sem se perder nelas? português uma boa tradução para mindfulness; que havia necessidade de definir atenção plena em linguagem mais simples possível; que embora as palavras fossem simples, os conteúdos abordados pelo questionário não eram familiares; e que se houvesse uma maior explicação em cada item, estes seriam mais facilmente compreendidos pela população brasileira em geral.

Esses apontamentos do comitê direcionaram a criação de duas versões. A versão-2 (Tabela 2) 
Tabela 2. continuação

\begin{tabular}{|c|c|c|c|c|}
\hline $\begin{array}{l}\text { versão original } \\
\text { Inglês }\end{array}$ & $\begin{array}{l}\text { versão-2 } \\
\text { Pré-teste-1 }\end{array}$ & $\begin{array}{l}\text { Exemplos de comentários } \\
\text { mais comuns ou } \\
\text { relevantes para a Versão-2 } \\
\text { Pré-teste } 1\end{array}$ & $\begin{array}{c}\text { Falta de } \\
\text { clareza para } \\
\text { a Versão-2 } \\
\text { Pré-teste } 1\end{array}$ & versão-4 \\
\hline $\begin{array}{l}\text { 11. In difficult } \\
\text { situations, I can } \\
\text { pause without } \\
\text { immediately } \\
\text { reacting. }\end{array}$ & $\begin{array}{l}\text { 11. Em situações } \\
\text { difíceis, eu consigo } \\
\text { parar um pouco sem } \\
\text { reagir de imediato. }\end{array}$ & $\begin{array}{l}\text { Sem comentários específicos. } \\
\text { "Na verdade todas as } \\
\text { perguntas são difíceis, não são } \\
\text { fáceis." }\end{array}$ & $1(2 \%)$ & $\begin{array}{l}\text { 11. Em situações complicadas, } \\
\text { podemos agir impulsivamente ou, } \\
\text { conseguimos parar um pouco e } \\
\text { responder com mais consciência do } \\
\text { que estamos sentindo e fazendo. } \\
\text { - Em situações difíceis, com que } \\
\text { frequência você conseguiu parar um } \\
\text { pouco sem reagir de imediato? }\end{array}$ \\
\hline $\begin{array}{l}\text { 12. I experience } \\
\text { moments of inner } \\
\text { peace and ease, even } \\
\text { when things get } \\
\text { hectic and stressful. }\end{array}$ & $\begin{array}{l}\text { 12. Experimento } \\
\text { momentos de calma } \\
\text { e paz interior, mesmo } \\
\text { quando a situação } \\
\text { parece ter muitas } \\
\text { tarefas e estresse. }\end{array}$ & $\begin{array}{l}\text { "paz interior?"; "seria reflexivo, } \\
\text { centralizado, equilibrado?" }\end{array}$ & $5(12 \%)$ & $\begin{array}{l}\text { 12. Vivemos momentos de } \\
\text { calma e paz interior quando nos } \\
\text { sentimos equilibrados e quando } \\
\text { estamos confiantes e abertos } \\
\text { para o que pode acontecer. } \\
\text { - Com que frequência você } \\
\text { experimentou momentos de calma } \\
\text { e paz interior, mesmo quando a } \\
\text { situação tinha muitas tarefas e } \\
\text { parecia estressante? }\end{array}$ \\
\hline $\begin{array}{l}\text { 13. I am impatient } \\
\text { with myself and with } \\
\text { others. }\end{array}$ & $\begin{array}{l}\text { 13. Eu me sinto } \\
\text { impaciente comigo } \\
\text { mesmo e com os } \\
\text { outros. }\end{array}$ & $\begin{array}{l}\text { "eu me sinto impaciente } \\
\text { com relação a quê, em que } \\
\text { situação?" }\end{array}$ & $1(2 \%)$ & $\begin{array}{l}\text { 13. Somos impacientes quando } \\
\text { demonstramos inquietação, } \\
\text { nos queixamos à toa e não nos } \\
\text { conformamos em esperar. } \\
\text { - Com que frequência você foi } \\
\text { impaciente consigo mesmo e com } \\
\text { os outros? }\end{array}$ \\
\hline $\begin{array}{l}\text { 14. I am able to } \\
\text { smile when I notice } \\
\text { how I sometimes } \\
\text { make life difficult. }\end{array}$ & $\begin{array}{l}\text { 14. Eu consigo sorrir } \\
\text { e achar graça quando } \\
\text { percebo que, às vezes } \\
\text { eu torno a minha vida } \\
\text { mais difícil. }\end{array}$ & $\begin{array}{l}\text { "não entendi"; "o que é tornar } \\
\text { a vida mais difícil?"; "sorrir } \\
\text { quando torna a vida difícil? } \\
\text { Não entendi" }\end{array}$ & $6(15 \%)$ & $\begin{array}{l}\text { 14. Tornamos a vida mais difícil } \\
\text { quando nossas escolhas e atitudes } \\
\text { criam situações mais duras e pesadas } \\
\text { para nós mesmos. Nessa situação, } \\
\text { podemos ficar nos criticando, ou } \\
\text { podemos também achar graça disso. } \\
\text { - Com que frequência você } \\
\text { conseguiu achar graça quando } \\
\text { percebeu que você mesmo estava } \\
\text { tornando a sua vida mais difícil? }\end{array}$ \\
\hline
\end{tabular}

que é semelhante à versão síntese da etapa anterior e a versão-3 (exemplos no Quadro 1) a qual possui um texto ilustrativo para cada item.

O tempo médio de preenchimento da versão-2 foi de 5 minutos e meio (variou de 1 a 16 minutos) e da versão-3 (que possuía o texto ilustrativo) foi de 10 minutos (variou de 6 a 23 minutos).

Ao analisar a frequência de relato de falta de clareza para a versão-2 (Tabela 2), constatou-se que $41 \%$ dos participantes do pré-teste-1 apontaram que a escala de resposta era confusa por possuir categorias muito semelhantes. Além dis- so, dez dos quatorze itens foram apontados como não claros por pelo menos $10 \%$ dos sujeitos. Os itens mais frequentemente citados como pouco claros foram os de número 1, 7, 8, 10 e 14 .

Alguns comentários e questionamentos realizados pelos participantes do pré-teste- 1 podem ser observados na Tabela 2. Estes ilustram a dificuldade de entendimento das ideias e de comportamentos abordados em cada item da versão-2. Diante disso, foi identificada a necessidade de mudanças na escala de resposta e de uma melhor explicação em cada item do questionário. 
Quadro 1. Os itens 1, 7, 8 e 10 como exemplo da versão-3 utilizada no pré-teste-1 do processo de adaptação cultural do Freiburg Mindfulness Inventory para o português no Brasil.

\begin{tabular}{|c|c|c|c|c|c|}
\hline \multirow[b]{2}{*}{ Texto ilustrativo } & \multirow[b]{2}{*}{ Afirmação } & \multicolumn{4}{|c|}{ Considere os últimos 30 dias. } \\
\hline & & $\begin{array}{l}\text { Quase } \\
\text { nunca }\end{array}$ & $\begin{array}{c}\text { De vez em } \\
\text { quando }\end{array}$ & Frequentemente & $\begin{array}{l}\text { Quase } \\
\text { sempre }\end{array}$ \\
\hline $\begin{array}{l}\text { A cada momento, talvez não saibamos } \\
\text { exatamente o que está para acontecer. } \\
\text { Nossa atitude pode ser de querer } \\
\text { receber, estar disposto e aberto para o } \\
\text { que venha a acontecer, ou, de querer } \\
\text { evitar, resistir, não querer viver o que } \\
\text { está acontecendo. }\end{array}$ & $\begin{array}{l}\text { 1. Eu estou } \\
\text { aberto para } \\
\text { experimentar } \\
\text { o momento } \\
\text { presente. }\end{array}$ & $\square$ & $\square$ & $\square$ & $\square$ \\
\hline $\begin{array}{l}\text { No dia a dia, quando estamos em } \\
\text { um lugar fazendo uma atividade, às } \\
\text { vezes podemos nos pegar pensando, } \\
\text { imaginando viver ou revivendo uma } \\
\text { situação na qual fazíamos outra } \\
\text { coisa em outro lugar. Outras vezes, } \\
\text { podemos perceber que estamos com a } \\
\text { atenção presente exatamente no lugar } \\
\text { em que estamos e na atividade que } \\
\text { estamos fazendo, ou seja, nos sentimos } \\
\text { conectados com a experiência do } \\
\text { aqui-e-agora. }\end{array}$ & $\begin{array}{l}\text { 7. Eu me sinto } \\
\text { conectado } \\
\text { com a minha } \\
\text { experiência do } \\
\text { aqui-e-agora. }\end{array}$ & $\square$ & $\square$ & $\square$ & $\square$ \\
\hline $\begin{array}{l}\text { No dia-a-dia, acontecem coisas que } \\
\text { eu posso perceber como erradas ou } \\
\text { desagradáveis e outras como corretas e } \\
\text { prazerosas. Quando acontecem coisas } \\
\text { desagradáveis, podemos reconhecer e } \\
\text { aceitar, ou seja, nos colocar dispostos a } \\
\text { receber o fato de que elas aconteceram. } \\
\text { Outras vezes, resistimos, lutamos } \\
\text { contra, nos condenamos e nos } \\
\text { comportamos como querendo achar } \\
\text { que isso não fosse verdade. }\end{array}$ & $\begin{array}{l}\text { 8. Eu aceito } \\
\text { experiências } \\
\text { desagradáveis. }\end{array}$ & $\square$ & $\square$ & $\square$ & $\square$ \\
\hline $\begin{array}{l}\text { No dia-a-dia, podem acontecer } \\
\text { muitas coisas que geram emoções. } \\
\text { Algumas vezes, conseguimos identificar } \\
\text { estas emoções e perceber o que está } \\
\text { acontecendo. Outras vezes, vivemos } \\
\text { estas emoções como se elas nos } \\
\text { dominassem, como se estivéssemos } \\
\text { perdidos nelas. }\end{array}$ & $\begin{array}{l}\text { 10. Eu observo } \\
\text { minhas emoções, } \\
\text { sem me perder } \\
\text { nelas. }\end{array}$ & $\square$ & $\square$ & $\square$ & $\square$ \\
\hline
\end{tabular}

Com relação à versão-3 (que continha o texto ilustrativo), $74 \%$ dos indivíduos relatou que os itens podiam ser entendidos mais facilmente do que a versão-2. No entanto, algumas pessoas relataram dificuldade em sustentar a atenção devido aos textos ilustrativos serem muito longos.
Alguns sujeitos também apontaram que os textos traziam ideias e palavras que podiam mudar a interpretação da questão ou que os direcionavam a considerar todo o texto ilustrativo, em vez de somente a afirmação correspondente ao item questionado. 
Dentre os relatos e comentários realizados pelos indivíduos quando compararam a versão-2 (mais curta) com a versão-3 (com texto ilustrativo) estão: “a versão curta fica uma questão genérica, só joga, e as perguntas são muito parecidas"; “a versão curta é mais direta, objetiva, você não perde a atenção"; "na versão curta, fico confuso no que pensar pra responder"; "na versão curta a gente entende, mas ainda fica um pouco confuso, com o texto fica mais claro"; "o texto ilustrativo facilitou eu entender o que a questão estava querendo dizer, mas tomou mais tempo para reflexão"; "com o texto ilustrativo respondo com mais segurança”; "os textos ilustrativos são longos e eu fui me perdendo"; "no texto ilustrativo tem coisas que leva a raciocinar de outra forma, às vezes é questão de uma palavra e dá outro sentido"; "o texto te faz pensar em outras possibilidades e isso requer uma resposta mais elaborada".

Devido aos diversos relatos, opiniões e dificuldades de entendimento de vários itens do instrumento, considerou-se que nenhuma das versões (versão-2 ou versão-3) estava adequada para a população brasileira em geral.

\section{Revisão pelo comitê de especialistas-2 e pré-teste-2}

Considerando as informações levantadas no pré-teste-1 criou-se a versão-4 (Tabela 2). Esta apresentou mudanças de palavras na escala de respostas, utilizou um texto ilustrativo mais curto comparado à versão-3 e continha uma pergunta em vez de uma afirmação em primeira pessoa. Esta versão foi novamente submetida ao comitê de especialistas para avaliação da clareza e equivalências com a versão original.

Apesar da versão-4 ter sido avaliada como clara, foi considerada pouco equivalente à original pelo comitê, principalmente em razão da grande diferença do formato dos itens com relação ao instrumento original. Deste modo, criou-se a versão-5, na qual os itens foram elaborados em primeira pessoa. $\mathrm{Na}$ versão 5 os detalhes explicativos sobre o comportamento a ser avaliado foram incluídos no próprio item. Desta forma, ao mesmo tempo em que o formato se aproximou ao original, foi possível trazer clareza às ideias apresentadas. $\mathrm{O}$ título do instrumento foi mantido em inglês e se adicionou um subtítulo explicativo "Questionário de percepção de comportamentos relacionados à atenção plena”. O comitê de especialistas avaliou a versão- 5 como clara e equivalente à versão original, e esta então seguiu para ser avaliada pela população em geral por meio do pré-teste- 2 .
O texto de orientação do questionário da versão-5 foi compreendido de forma clara por $100 \%$ da amostra, enquanto a escala de respostas foi por 93\%. Com relação aos itens, 96 a 100\% dos participantes entenderam claramente 10 das 14 afirmações. A menor frequência de claro entendimento foi apresentada no item 1 (92\%), seguido pelos itens 9 e 11 (93\%) e 14 (94\%).

Apesar de poucos participantes apontarem ainda dúvidas com relação a alguns itens, a maioria dos comentários expressou o fácil entendimento das ideias apresentadas. Por exemplo: "É fácil de entender, embora questione algo que não seja cotidiano para mim”; "a expressão a cada momento me pareceu um pouco confusa"; "precisei ler mais de uma vez"; "muito subjetivo, mas é possível entender"; "questões práticas e objetivas de autorreflexão”. Assim, incorporaram-se alguns pequenos ajustes na versão-5 para que fosse criado o Freiburg Mindfulness Inventory adaptado para o Brasil (FMI-Br) (Quadro 2). Esta versão brasileira foi retrotraduzida para o inglês e recebeu apreciação positiva pelo autor do instrumento original.

\section{Discussão}

O FMI-Br é um dos primeiros instrumentos de autorrelato culturalmente adaptado para brasileiros que aborda mindfulness com base teórica alinhada à psicologia budista. Durante cada etapa deste estudo, além de serem consideradas as equivalências conceituais e semânticas com o instrumento original, procurou-se criar uma versão que também pudesse responder às limitações e desafios próprios de se avaliar mindfulness por meio de um instrumento de autorrelato.

Alguns autores identificam essas limitações e desafios como: (a) a não familiaridade do conceito para a maioria da população; (b) a definição não consensual entre pesquisadores, praticantes, literatura acadêmica e literatura da psicologia budista; (c) a modesta experiência pessoal com a prática da meditação dos próprios pesquisadores; (d) a operacionalização do conceito de mindfulness nos instrumentos que parece corresponder mais aos interesses de cada pesquisador do que a um profundo conhecimento do conceito proveniente de antigas tradições; (e) o diferente entendimento dos itens das escalas por praticantes e não praticantes de meditação ${ }^{1,27,34}$.

Mindfulness, nos últimos 30 anos, tem sido recontextualizado a um ambiente laico. Em seu cenário original histórico, esta prática envolve, 
Quadro 2. Freiburg Mindfulness Inventory adaptado para o Brasil (FMI-Br).

Freiburg Mindfulness Inventory adaptado para o Brasil (FMI-Br)

Questionário sobre a percepção de comportamentos relacionados à atenção plena

O objetivo desse questionário é identificar como você acha que está a sua atenção e o seu comportamento em diferentes situações. Considere os últimos ___ dias para você se avaliar em cada item. Responda cada item da melhor forma que você puder. Seja honesto(a) e espontâneo(a). Não há respostas 'certas' ou 'erradas', nem respostas 'boas' ou 'ruins'. O que é importante para nós é a sua própria experiência pessoal. Agradecemos o seu empenho e a sua disponibilidade!

\begin{tabular}{|c|c|c|c|c|}
\hline & Raramente & $\begin{array}{l}\text { De vez em } \\
\text { quando }\end{array}$ & $\begin{array}{l}\text { Com alguma } \\
\text { frequência }\end{array}$ & $\begin{array}{l}\text { Quase } \\
\text { sempre }\end{array}$ \\
\hline $\begin{array}{l}\text { 1. Eu estou aberto(a), disposto(a) pra viver as coisas que } \\
\text { podem acontecer a cada instante. }\end{array}$ & $\square$ & $\square$ & $\square$ & $\square$ \\
\hline $\begin{array}{l}\text { 2. Eu presto atenção às sensações do meu corpo (pela } \\
\text { pele, sabores na boca, minha postura, etc.) quando estou } \\
\text { comendo, cozinhando, fazendo limpeza ou conversando. }\end{array}$ & $\square$ & $\square$ & $\square$ & $\square$ \\
\hline $\begin{array}{l}\text { 3. Quando eu noto que estou pensando no futuro, } \\
\text { no passado ou em coisas que me deixam disperso(a), } \\
\text { calmamente trago a minha atenção para o que estou } \\
\text { vivendo aqui e agora. }\end{array}$ & $\square$ & $\square$ & $\square$ & $\square$ \\
\hline $\begin{array}{l}\text { 4. Eu consigo reconhecer as minhas qualidades e admirar a } \\
\text { mim mesmo(a). }\end{array}$ & $\square$ & $\square$ & $\square$ & $\square$ \\
\hline $\begin{array}{l}\text { 5. Eu olho pra dentro de mim mesmo(a) e presto atenção } \\
\text { ao que está me levando a fazer determinada coisa. }\end{array}$ & $\square$ & $\square$ & $\square$ & $\square$ \\
\hline $\begin{array}{l}\text { 6. Eu olho pros meus erros e dificuldades sem ficar me } \\
\text { julgando. }\end{array}$ & $\square$ & $\square$ & $\square$ & $\square$ \\
\hline $\begin{array}{l}\text { 7. A minha atenção está voltada para o local onde estou e } \\
\text { para a atividade que estou realizando a cada momento. }\end{array}$ & $\square$ & $\square$ & $\square$ & $\square$ \\
\hline $\begin{array}{l}\text { 8. Eu consigo conviver com uma notícia, situação, emoção } \\
\text { ou sensação que não gosto, sem querer mudá-la ou fugir } \\
\text { dela. }\end{array}$ & $\square$ & $\square$ & $\square$ & $\square$ \\
\hline $\begin{array}{l}\text { 9. Mesmo quando as coisas não ocorrem como eu planejei } \\
\text { ou parecem dar errado, eu procuro dar apoio a mim } \\
\text { mesmo(a). }\end{array}$ & $\square$ & $\square$ & $\square$ & $\square$ \\
\hline $\begin{array}{l}\text { 10. Eu presto atenção às minhas próprias emoções e } \\
\text { consigo agir sem que elas tomem conta de mim. }\end{array}$ & $\square$ & $\square$ & $\square$ & $\square$ \\
\hline $\begin{array}{l}\text { 11. Em situações difíceis, eu consigo parar um pouco e não } \\
\text { reagir de imediato. }\end{array}$ & $\square$ & $\square$ & $\square$ & $\square$ \\
\hline $\begin{array}{l}\text { 12. Mesmo quando eu fico cheio(a) de tarefas e estressado, } \\
\text { eu lido com esta situação e consigo me sentir bem. }\end{array}$ & $\square$ & $\square$ & $\square$ & $\square$ \\
\hline $\begin{array}{l}\text { 13. Eu me sinto impaciente comigo mesmo e com os } \\
\text { outros. }\end{array}$ & $\square$ & $\square$ & $\square$ & $\square$ \\
\hline $\begin{array}{l}\text { 14. Quando eu faço algo que complicou a minha própria } \\
\text { vida, eu não fico só me criticando, mas consigo achar graça } \\
\text { disso. }\end{array}$ & $\square$ & $\square$ & $\square$ & $\square$ \\
\hline
\end{tabular}


além da atenção e cognição, também a ação recíproca de uma rede dinâmica e complexa de dimensões afetivas (bondade, paciência, tolerância, gentileza, empatia, aceitação-sem fuga, abertura) e éticas (não ferir a si e outros, não mentir, não roubar $)^{7}$.

Apesar disso, a maioria dos instrumentos disponíveis na literatura se baseou em uma operacionalização contemporânea de mindfulness, o que simplifica a sua mensuração. A adaptação da Escala Filadelfia de Mindfulness para adultos brasileiros parece não ter apresentado maiores complicações $^{32}$.

De forma diferenciada, o FMI foi criado explicitamente com base teórica da psicologia budis$\mathrm{ta}^{31,34,35}$. Isto contribuiu para alguns participantes terem julgado as questões como contraditórias ou mesmo como ações que jamais haviam feito ou pensado antes. Isso não é algo que acontece exclusivamente com brasileiros, mas pode acontecer com qualquer indivíduo que não teve nenhuma experiência anterior com mindfulness ${ }^{27}$.

Um estudo qualitativo apontou que alemães sem experiência meditativa apresentaram uma interpretação variada e diferente do propósito da questão, em sua maioria nos itens relacionados ao fator presença $(1,2,3,5,7,8,10$ e 12) do FMI. Os autores sugerem que a ambiguidade de palavras como "awareness" (consciência), "to notice" (perceber), "to judge" (julgar) e "experience" (experiência) utilizadas nos itens do questionário podem ter ajudado para esta ocorrência ${ }^{41}$.

O presente estudo apresentou achados muito semelhantes na amostra de brasileiros. Para responder à dificuldade de compreensão e aos outros desafios da própria ação de avaliar mindfulness pelo autorrelato, o presente estudo contou com a participação de ordenados budistas, profissionais da saúde, professores de meditação, linguistas e entrevistas com a população leiga para criar uma versão final que fosse ao mesmo tempo equivalente ao original, conceitualmente rigorosa e que possuísse frases e ideias sucintas, ilustrativas e de fácil entendimento pelos brasileiros.

A opção pela inclusão do subtítulo explicativo ao nome do instrumento original ("Questionário de percepção de comportamentos relacionados à atenção plena") deu-se pelos seguintes motivos: (a) a sugestão do comitê de especialistas para manter na versão adaptada o nome do instrumento original; (b) o não entendimento pela população brasileira do termo mindfulness; (c) o argumento de que os instrumentos de autorrelato não deveriam declarar que mensuram diretamente mindfulness e sim comportamentos relacionados a este construto/prática ${ }^{34,50} ;$ (d) a possível diferença entre mindfulness autorrelatado e a prática de fato cotidiana de mindfulness ${ }^{34}$.

Além disso, para se evitar o uso dessas duas palavras não familiares na cultura brasileira, mindfulness e atenção plena, no texto de orientação do instrumento, optou-se por descrever o objetivo do questionário de forma geral como sendo "identificar como você acha que está a sua atenção e o seu comportamento em diferentes situações".

Este estudo utilizou importantes elementos em sua metodologia para a adaptação de um instrumento de medida cujos resultados possam ser comparados entre populações de diferentes locais e culturas. Porém, uma de suas limitações é a sua amostra predominantemente de mulheres, adultas jovens e de alta renda e escolaridade. Outros estudos serão necessários para avaliar a sua adequação em populações brasileiras específicas e as características da sua estrutura fatorial, confiabilidade e validade. Sugere-se que tais estudos abordem a uniformidade da interpretação dos itens em diferentes grupos ${ }^{30,31}$, característica particularmente importante ao investigar a autopercepção de mindfulness.

Uma recente análise do FMI utilizando a Teoria da resposta ao item identificou uma diferença de compreensão entre jovens e idosos e sugeriu outros aperfeiçoamentos como uma versão alternativa de 13 itens com maior validade interna segundo o modelo Rasch ${ }^{40}$.

A abordagem de mindfulness por meio de instrumentos de autorrelato tem pouco mais de uma década. Neste contexto, existem ainda muitas investigações a serem realizadas sobre o emprego destes questionários. Mesmo diante do presente estudo parece ser pertinente questionar se é possível expressar mindfulness em uma linguagem que não seja facilmente mal interpretada e que não pressuponha a experiência prévia com a sua prática. Desta forma, sugere-se ainda cautela na interpretação dos resultados provenientes de pesquisas que utilizam tais instrumentos ${ }^{41}$.

Futuros estudos na população brasileira deverão investigar os possíveis aperfeiçoamentos necessários na versão brasileira adaptada do Freiburg Mindfulness Inventory. Por abordar novos conceitos e práticas, outra questão a ser avaliada é se o FMI-Br pode também servir como uma ferramenta auxiliar no desenvolvimento de mindfulness.

Dentre os grandes desafios presentes no campo da saúde está a interação de práticas de saúde convencionais, complementares e alternativas, 
incluindo relações de continuidade, ruptura, hibridização e negociação entre diferentes sistemas do desenvolvimento cultural ${ }^{51}$. Este instrumento poderá contribuir com os profissionais e pesquisadores brasileiros para a produção de legitimidade teórica das intervenções baseadas em mindfulness. Além do diálogo com a ciência moderna, que este estudo inicial sobre mindfulness possa também apoiar uma compreensão que ultrapasse a racionalidade biológica na saúde e incentive a integralidade do cuidado, a humanização das relações e mudanças na educação em saúde ${ }^{51,52}$.

\section{Conclusão}

A adaptação cultural do Freiburg Mindfulness Inventory foi realizada em múltiplas fases com a participação de especialistas e da população em geral. Destaca-se a inclusão de explicações adicionais em cada item para lidar com a não familiaridade dos brasileiros com os comportamentos abordados pelo instrumento. Esta estratégia possibilitou a criação de uma versão brasileira que se mostrou de fácil entendimento e de adequada equivalência com a versão original. Este é um dos primeiros instrumentos de autorrelato existentes na língua portuguesa que aborda mindfulness com base teórica alinhada à psicologia budista.

Futuros estudos são necessários para analisar as propriedades psicométricas do FMI na cultura brasileira. O FMI-Br poderá ter relevante aplicação na avaliação da população em geral e na avaliação do efeito e de mecanismos das intervenções baseadas em mindfulness, em implantação e expansão nos serviços de saúde, educação, gestão e outros setores da sociedade no mundo e no Brasil.

\section{Colaboradores}

MS Hirayama e NMC Alexandre trabalharam na elaboração do projeto, coleta e interpretação dos dados, redação e revisão crítica do artigo; D Milani, NF de Barros e RCM Rodrigues trabalharam na interpretação dos dados, redação e revisão crítica do artigo.

\section{Agradecimentos}

A cada um dos especialistas que contribuíram na revisão do questionário adaptado.

À Coordenação de Aperfeiçoamento de Pessoal de Nível Superior (CAPES-Brasil), ao Conselho Nacional de Desenvolvimento Científico e Tecnológico (CNPq-Brasil) e ao Fundo de apoio ao ensino, à pesquisa e à extensão da Universidade Estadual de Campinas (FAEPEX-UNICAMP). 


\section{Referências}

1. Grossman P, Dam NTV. Mindfulness, by any other name...: trials and tribulations of sati in western psychology and science. Contemp Budd 2011; 12(1):219139.

2. Gunaratana BH. Mindfulness in Plain English. Boston: Wisdom; 1992.

3. Kabat-Zinn J. Mindfulness-based interventions in context: Past, present, and future. Clin Psychol Sci Prac 2003; 10(2):144-156.

4. Brown KW, Ryan RM, Creswell JD. Mindfulness: Theoretical foundations and evidence for its salutary effects. Psychol Inq 2007; 18(4):211-237.

5. Bishop SR, Lau M, Shapiro S, Carlson L, Anderson ND, Carmody J, Segal ZV, Abbey S, Speca M, Velting D, Devins G. Mindfulness: a proposed operational definition. Clin Psychol Sci Prac 2003; 11(3):230-241.

6. Eberth J, Sedlmeier P. The Effects of Mindfulness Meditation: A Meta-Analysis. Mindfulness 2012; 3(3):174189.

7. Grossman P. Mindfulness for Psychologists: Paying Kind Attention to the Perceptible. Mindfulness 2010; $1(2): 87-97$

8. Vandenberghe L, Assunção AB. Concepções de mindfulness em langer e Kabat-Zinn: um encontro da ciência ocidental com a espiritualidade oriental. Contextos Clínic 2009; 2(2):124-135.

9. Cullen M. Mindfulness-Based Interventions: An Emerging Phenomenon. Mindfulness 2011; 2(3):186-193.

10. Kabat-Zinn J. Some reflections on the origins of MBSR, skillfull means, and the trouble with maps. Contemp Budd 2011; 12(1):282-306.

11. Kabat-Zinn J. An out-patient program in Behavioral Medicine for chronic pain patients based on the practice of mindfulness meditation: Theoretical considerations and preliminary results. Gen Hosp Psych 1982; 4(1):33-47.

12. Vandenbergh L, Souza ACA. Mindfulness nas terapias cognitivas e comportamentais. Rev Bras Ter Cogn 2006; 2(1):35-44.

13. Segal ZV, Williams MG, Teasdale JD. Mindfulness based cognitive behavior therapy for depression. A new approach to preventing relapse. New York: Guildford; 2002.

14. Grossman P, Niemann L, Schmidt S, Walach H. Mindfulness-based stress reduction and health benefits: A meta-analysis. J Psychos Res 2004; 57(1):35-43.

15. Baer R. Mindfulness training as a clinical intervention: A conceptual and empirical review. Clin Psychol Sci Pract 2003; 10(2):125-143.

16. Gockel A. The promise of mindfulness for clinical practice education. Smith Coll Stud Soc Work 2010; 80(2-3):248-268.

17. Oken BS, Fonareva I, Haas M, Wahbeh H, Lane JB, Zajdel D, Amen A. Pilot controlled trial of mindfulness meditation and education for dementia caregivers. $J$ Altern Complement Med 2010; 16(10):1031-1038.

18. Franco C, Mañas I, Cangas AJ, Moreno E, Gallego J. Reducing teachers' psychological distress through a mindfulness training program. Span J Psychol 2010; 13(2):655-666.

19. Valentine S, Godkin L, Varca PE. Role Conflict, Mindfulness, and Organizational Ethics in an Education-Based Healthcare Institution. J Busin Eth 2010; 94(3):455-469.
20. Edenfield TM, Saeed SA. An update on mindfulness meditation as a self-help treatment for anxiety and depression. Psychol Res Behav Manag 2012; 5:131-141.

21. Khanna S, Greeson JM. A narrative review of yoga and mindfulness as complementary therapies for addiction. Complement Ther Med 2013; 21(3):244-252.

22. Wanden-Berghe RG, Sanz-Valero J, Wanden-Berghe C. The application of mindfulness to eating disorders treatment: a systematic review. Eat Disord 2011; 19(1):34-48.

23. Ong JC, Ulmer CS, Manber R. Improving sleep with mindfulness and acceptance: a metacognitive model of insomnia. Behav Res Ther 2012; 50(11):651-660.

24. Chiesa A, Serretti A. Mindfulness-based interventions for chronic pain: a systematic review of the evidence. $J$ Altern Complement Med 2011; 17(1):83-93.

25. Shennan C, Payne S, Fenlon D. What is the evidence for the use of mindfulness-based interventions in cancer care? A review. Psychooncology 2011; 20(7):681-697.

26. Sauer S, Lynch S, Walach H, Kohls N. Dialectics of mindfulness: implications for western medicine. Philos Ethics Humanit Med 2011; 6:10.

27. Grossman P. Defining mindfulness by how poorly I think I pay attention during everyday awareness and other intractable problems for psychology's (re)invention of mindfulness: comment on Brown et al. Psychol Assess 2011; 23(4):1034-1040. (Discussion 41-6).

28. Brown KW, West AM, Loverich TM, Biegel GM. Assessing adolescent mindfulness: validation of an adapted mindful attention awareness scale in adolescent normative and psychiatric populations. Psychol Assess 2011; 23(4):1023-1033.

29. Baer RA. Measuring mindfulness. Contemp Budd 2011; 12(1):241-261.

30. Bergomi C, Tschacher W, Kupper Z. The Assessment of Mindfulness with Self-Report Measures: Existing Scales and Open Issues. Mindfulness 2012; 4(3):191-202.

31. Sauer S, Walach H, Schmidt S, Hinterberger T, Lynch S, Büssing A, Kohls N. Assessment of Mindfulness: Review on State of the Art. Mindfulness 2012; 4(1):3-27.

32. Silveira AC, Castro TG, Gomes WB. Adaptação e validação da Escala Filadélfia de Mindfulness para adultos brasileiros. Psico-USF 2012; 17(2):215-223.

33. Barros VV. Evidências de validade da Escala de Atenção e Consciência Plenas (MAAS) e do Questionário das Facetas de Mindfulness (FFMQ-BR) entre usuários de tabaco e população geral [dissertação]. Juiz de Fora: Universidade Federal de Juiz de Fora; 2013.

34. Grossman P. On measuring mindfulness in psychosomatic and psychological research. J Psychosom Res 2008; 64(4):405-408.

35. Buchheld N, Grossman P, Walach H. Measuring mindfulness in insight meditation (vipassana) and meditation-based psychotherapy: the development of the Freiburg Mindfulness Inventory (FMI). J Medit Medit Res 2001; 1:11-34.

36. Walach H, Buchheld N, Buttenmüller V, Kleinknecht N, Schmidt S. Measuring mindfulness-the Freiburg Mindfulness Inventory (FMI). Pers Individ Dif 2006; 40(8):1543-1555.

37. Trousselard M, Steiler D, Raphel C, Cian C, Duymedjian R, Claverie D, Canini F. Validation of a French version of the Freiburg Mindfulness Inventory - short version: relationships between mindfulness and stress in an adult population. Biopsychosoc Med 2010; 4:8. 
38. Chen SY, Zhou, RL. Validation of a Chinese Version of th Freiburg Mindfulness Inventory-Short Version. Mindfulness 2013; Abril 4.

39. Kohls N, Sauer S, Walach H. Facets of mindfulness - Results of an online study investigating the Freiburg mindfulness inventory. Pers Individ Dif 2009; 46(2):224-230.

40. Sauer S, Ziegler M, Danay E, Ives J, Kohls N. Specific Objectivity of Mindfulness - A Rasch Analysis of the Freiburg Mindfulness Inventory. Mindfulness 2013; 4(1):45-54.

41. Belzer F, Schmidt S, Lucius-Hoene G, Schneider J, Orellana-Rios C, Sauer S. Challenging the Construct Validity of Mindfulness Assessment-a Cognitive Interview Study of the Freiburg Mindfulness Inventory. Mindfulness 2012; 4(1):33-44.

42. Leigh J, Bowen S, Marlatt GA. Spirituality, mindfulness and substance abuse. Addict Behav 2005; 30(7):13351341.

43. Jimenez SS, Niles BL, Park CL. A mindfulness model of affect regulation and depressive symptoms: Positive emotions, mood regulation expectancies, and self-acceptance as regulatory mechanisms. Pers Individ Dif 2010; 49(6):645-650.

44. Zeidan F, Martucci KT, Kraft RA, Gordon NS, McHaffie JG, Coghill RC. Brain mechanisms supporting the modulation of pain by mindfulness meditation. J Neurosci 2011; 31(14):5540-5548.

45. Schutte NS, Malouff JM. Emotional intelligence mediates the relationship between mindfulness ad subjective well-being. Pers Individ Dif 2011; 50(7):1116-1119.

46. Beaton DE, Bombardier C, Guillemin F, Ferraz MB. Guidelines for the process of cross-cultural adaptation of self-report measures. Spine 2000; 25(24):3186-3191.

47. Alexandre NMC, Coluci, MZO. Validade de conteúdo nos processos de construção e adaptação de instrumentos de medida. Cien Saude Colet 2011; 16(7):30613067.

48. Coluci MZO, Milani D, Alexandre NMC. Construção de Instrumentos de medida na área da saúde. Cien Saude Colet. No prelo 2014.

49. Brasil. Ministério da Saúde (MS). Conselho Nacional de Saúde. Resolução no 196 de 10 de outubro de 1996. Diretrizes e Normas Regulamentadoras de Pesquisas Envolvendo Seres Humanos. Diário Oficial da União 1996; 16 out.

50. Malinowski P. Mindfulness as psychological dimension: concepts and applications. Irish J Psychol 2008; 29(1-2):155-166.

51. Nascimento MC, Barros NF, Nogueira MI, Luz MT. A categoria racionalidade médica e uma nova epistemologia em saúde. Cien Saude Colet 2013; 18(12):35953604.

52. Otani MAP, Barros NF. A Medicina Integrativa e a construção de um novo modelo na saúde. Cien Saude Colet 2011; 16(3):1801-1811.

Artigo apresentado em 20/07/2013

Aprovado em 30/10/2013

Versão final apresentada em 08/11/2013 